\title{
PENGGUNAAN E-MARKETPLACE SEBAGAI MEDIASI ANTARA KEUNGGULAN E-COMMERCE DAN KINERJA MANAJEMEN RANTAI PASOKAN
}

\author{
Poppy Laksita Rini \\ Fakultas Ekonomi dan Bisnis Universitas Ahmad Dahlan \\ poppy.rini@mgm.uad.ac.id
}

Masuk : 31-03-2021, revisi : 06-05-2021, diterima untuk diterbitkan : 18-05-2021

\begin{abstract}
The development of information technology has increased the use of E-Commerce at both upstream and downstream processes of supply chain management. One type of ECommerce that was widely used by businesses and MSMEs is the E-Marketplace. Emarketplaces help to increase the efficiency and effectiveness of supply chain management activities, especially in the process of delivering goods or services to consumers. This study aims to see the relationship between the advantages of E-Commerce on the performance of supply chain management, with the role of E-Marketplace as an intermediary. This research examined the MSME sector in DIY Province, with a sample of 160 units has been taken. Based on the path analysis technique by using SPSS software, it was found that there was a positive and significant direct influence between the advantages of E-commerce on the supply chain management performance with the direct effect value of 0.189 . Furthermore, there was also the role of using E-Marketplace as a mediating variable on the indirect effect of E-commerce advantages on supply chain management performance with the indirect value of 0.195 .
\end{abstract}

Keywords: E-Commerce, E-Marketplace, Supply Chain Management, MSME

\begin{abstract}
Abstrak: Perkembangan teknologi informasi telah meningkatkan penggunaan E-Commerce dalam rantai pasokan di hulu maupun di hilir proses. Salah satu jenis E-Commerce yang banyak digunakan oleh pelaku bisnis dan UMKM adalah E-Marketplace. E-marketplace mampu meningkatkan efisiensi dan efektivitas aktivitas manajemen rantai pasokan khususnya dalam proses penyampaian barang atau jasa ke konsumen. Penelitian ini bertujuan untuk melihat hubungan antara keunggulan yang terdapat pada E-Commerce terhadap kinerja manajemen rantai pasokan, dengan penggunaan E-Marketplace perantara. Penelitian ini meneliti sektor UMKM di Provinsi DIY, dengan sampel yang diambil sebanyak 160 unit UMKM. Berdasarkan Teknik analisis jalur (Path Analysis) didapatkan bahwa terdapat pengaruh secara langsung yang positif dan signifikan antara keunggulan e-commerce terhadap kinerja manajemen rantai pasokan dengan nilai direct effect sebesar 0.189. Serta terdapat pula peran penggunaan EMarketplace sebagai variabel mediasi pada pengaruh tidak langsung antara keunggulan ecommerce terhadap kinerja manajemen rantai pasokan dengan nilai indirect effect sebesar 0.195 .
\end{abstract}

Kata kunci: E-Commerce, E-Marketplace, Manajemen Rantai Pasokan, UMKM

\section{PENDAHULUAN}

\section{Latar Belakang}

Pesatnya penggunaan internet saat ini membuat pelaku bisnis mampu melakukan aktivitas manajemen rantai pasokan baik pada aktivitas hulu hingga aktivitas hilir tanpa terkendala batasan fisik. Salah satu media internet yang banyak digunakan oleh para pelaku bisnis, tidak terkecuali usaha kecil menengah (UKM), adalah E-Commerce. Guang (2012) mengungkapkan bahwa E-Commerce memberikan dampak signifikan pada manajemen rantai pasokan suatu bisnis dengan memfasilitasi pengumpulan dan pemrosesan sebagian besar informasi secara cepat dan akurat. Porter (2001) menyebutkan bahwa E- Commerce memberi 
beberapa manfaat bagi proses bisnis seperti kemudahan bertransaksi kapan pun dan dimana pun dengan biaya yang lebih rendah. Awad (2007) dan Schneider (2006) menyimpulkan manfaat yang dapat diperoleh perusahaan dari penggunaan sistem E-Commerce dalam bisnis seperti: (1) Peningkatan penjualan; (2) Mengurangi total production to delivery time; (3) Mengurangi total biaya produksi; (4) Mengelola informasi dan pemesanan lebih efisien; (5) Mengurangi waktu untuk memperkenalkan produk baru; (6) Memberikan informasi terkait fluktuasi permintaan dan tren pada pelanggan; (7) Mempermudah dalam penyesuaian permintaan pelanggan; (8) Meningkatkan kecepatan pemrosesan transaksi bisnis.

Dalam ranah manajemen rantai pasokan, perkembangan teknologi informasi mampu meningkatkan penggunaan E-Commerce. Tujuan dari kinerja manajemen rantai pasokan adalah berupaya menghasilkan integrasi rantai pasokan yang lebih efektif dengan transparansi informasi lengkap dan alokasi optimal dalam proses penambahan nilai (Mentzer et al., 2001; Van der Vorst et al., 2002). Di sinilah keunggulan pada E- Commerce mampu membantu manajemen rantai pasokan mencapai tujuan kinerja tersebut secara lebih optimal. Berbagai perusahaan mulai mengintegrasikan E-Commerce pada manajemen rantai pasokan sebagai upaya penggunaan teknologi untuk meningkatkan kecepatan dan kelincahan proses operasional bisnis juga kepuasan pelanggan.

Salah satu jenis E-Commerce yang banyak digunakan oleh pelaku bisnis dan UMKM di Indonesia adalah E-Marketplace. Penggunaan E-marketplace mampu meningkatkan efisiensi dan efektivitas aktivitas manajemen rantai pasokan khususnya dalam proses penyampaian produk ke konsumen, dengan mengganti proses transaksi bisnis tradisional menjadi proses automasi elektronik serta meningkatkan basis konsumen dan rekanan dalam jual beli (Chong et al., 2010; Koch, 2003). Di Indonesia, keberadaan E-Marketplace ini mampu menjadi "tiket emas" untuk meningkatkan penjualan secara signifikan bagi pelaku UMKM. Kemudahan bertransaksi serta jaringan distribusi yang luas menjadikan E-marketplace di Indonesia berkembang pesat. Beberapa penelitian telah mengkaji pengaruh positif antara E-Commerce terhadap aspek bisnis lain seperti pada kinerja pemasaran (Ramanathan et al., 2012), rencana dan strategi bisnis (Alzahrani, 2019) dan kinerja keuangan (Kareem et al., 2014). Namun, hubungan antara E-Commerce dan kinerja manajemen rantai pasokan masih menjadi suatu fenomena perkembangan teknologi informasi dalam bisnis yang belum cukup banyak dikaji (Golicic et al., 2002).

\section{Tujuan Penelitian}

Penggunaan E-Marketplace mampu menjadi perantara yang memperkuat hubungan antara keunggulan pada E-Commerce terhadap kinerja manajemen rentai pasokan melalui beberapa manfaat yang diberikan. Minimnya penelitian terdahulu yang secara spesifik mengkaji hubungan antara ketiga aspek tersebut (Keunggulan E-Commerce, Penggunaan EMarketplace, dan Kinerja Manajemen Rantai Pasokan) menjadi suatu celah yang menarik untuk dikaji secara mendalam. Berdasarkan uraian tersebut, penelitian ini bertujuan untuk menganalisis hubungan antara keunggulan pada E-commerce terhadap kinerja manajemen rantai pasokan dengan penggunaan E-marketplace sebagai variabel mediasi.

\section{TINJAUAN PUSTAKA}

\section{Keunggulan E-Commerce}

Turban dan Volonino (2009) mendefinisikan E-Commerce sebagai aktivitas komersial untuk membeli dan menjual barang dan jasa melalui internet. E-commerce dipandang sebagai teknologi internet yang menyediakan kemampuan untuk membeli dan menjual secara online, seperti penciptaan pasar, proses pemesanan, manajemen rantai pasokan, dan protokol pembayaran (Hoffman \& Novak, 2000). Banyak perusahaan besar terus meningkatkan penggunaan E-commerce dalam manajemen rantai pasokan untuk memperkuat hubungan secara online dan terintegrasi dengan pemasok, distributor dan mitra bisnis, serta untuk melayani pelanggan secara lebih efektif (Zhu \& Kraemer, 2002). Awad (2007) 
mengungkapkan keunggulan yang dapat diperoleh dari menggunakan e-commerce seperti: (1) Biaya yang lebih rendah; (2) Ekonomis; (3) Potensi margin yang lebih tinggi; (4) Layanan pelanggan yang lebih baik; (5) Meningkatkan produktivitas; (6) Meningkatkan kinerja tim; dan (7) Kustomisasi kebutuhan dan permintaan konsumen.

\section{Pengunaan E-Marketplace}

Dou \& Chou (2002) mendefinisikan E-marketplace sebagai platform transaksi bisnis online untuk pembeli dan penjual. Turban et al (2017) menyatakan setidaknya terdapat tiga fungsi utama penggunaan E-Marketplace dalam aktivitas perusahaan yaitu: (1) Mempertemukan penjual dan pembeli yang cocok; (2) Memfasilitasi pertukaran informasi, barang, jasa, dan pembayaran dalam proses transaksi; (3) Menyediakan sebuah infrastruktur transaksi bisnis, termasuk di dalamnya hukum dan peraturan, untuk menciptakan fungsi pasar yang lebih efisien.

\section{Kinerja Manajemen Rantai Pasokan}

Chaffey (2009) mendefinisikan manajemen rantai pasokan sebagai bagian dalam organisasi yang bertugas melakukan koordinasi dari semua kegiatan terkait penyediaan dari pemasok (hulu) hingga penyaluran kepada pelanggan (hilir). Gunasekaran, Patel, dan Tirtiroglu (2001) mengklasifikan kinerja pada manajemen rantai pasokan yaitu:

1. Kinerja Perencanaan yang terdiri dari siklus pengembangan produk, metode pencatatan pesanan, total cycle time, akurasi tingkat peramalan, lead time, rasio produktivitas.

2. Kinerja Pengadaan yang terdiri dari hubungan dengan pemasok, kinerja pengiriman pemasok, lead time pemasok, harga yang ditawarkan pemasok, kualitas pasokan, dan purchase order cycle time.

3. Kinerja Produksi yang terdiri dari biaya manufaktur, utilisasi kapasitas, EOQ, efektivitas Master Production Schedule, production cycle time dan tingkat persediaan.

4. Kinerja Pengiriman/Penyampaian yang terdiri dari delivery lead time, efektivitas pengiriman, efektivitas metode invoice, dan total biaya distribusi.

5. Kinerja Pelayanan dan Kepuasan Konsumen yang terdiri dari kemampuan memenuhi kebutuhan spesifik konsumen, waktu merespon konsumen, dan customer perceived value terhadap produk.

\section{METODOLOGI PENELITIAN}

Penelitian ini dilakukan menggunakan metode penelitian kuantitatif dengan teknik pengambilan data menggunakan kuisioner yang disebar kepada pelaku UMKM di DIY. Teknik sampling dalam penelitian ini menggunakan non-probability purposive sampling dengan kriteria sampel merupakan pelaku UMKM yang melakukan aktivitas usaha di DIY, serta umur usaha telah berjalan lebih dari 1 tahun. Hair, et al, (2009) merumuskan penentuan jumlah sampel adalah 5 sampai 10 kali jumlah item pertanyaan. Pada penelitian ini terdapat 23 item pertanyaan dikali 5 maka minimal jumlah sampel adalah 115. Penelitian ini berhasil mendapatkan data dari 160 responden untuk kemudian diolah. Data yang berhasil didapatkan diolah menggunakan software SPSS dengan proses pengujian yaitu: (1) Uji Validitas instrument penelitian; (2) Uji reliabilitas instrument penelitian; (3) Uji regresi linier berganda antar variabel penelitian; (4) Analisis jalur (Path Analysis).

\section{HASIL DAN KESIMPULAN}

\section{Uji Validitas dan Reliabilitas Instrumen Penelitian}

Uji Validitas instrument penelitian ini menggunakan metode CFA dan didapatkan seluruh item pertanyaan dalam kuisioner memiliki nilai component matrix di atas 0.5 sehingga seluruh item pertanyaan dinyatakan valid. Uji reliabilitas menggunakan indikator Cornbach Alfa dimana variabel dinyatakan reliabel bila nilai Croncbach's Alfa berada di atas nilai 0.6. Seluruh variabel pada penelitian ini memiliki nilai Croncbach's Alfa di atas 0.6 sehingga dinyatakan reliabel. 
Tabel 1

Ringkasan Hasil Uji Validitas dan Reliabilitas

\begin{tabular}{|c|c|c|c|c|c|}
\hline \multirow[b]{2}{*}{ Variabel } & \multirow{2}{*}{$\begin{array}{c}\text { Item } \\
\text { Pertanyaan }\end{array}$} & \multicolumn{2}{|c|}{ Uji Validitas } & \multicolumn{2}{|c|}{ Uji Reliabilitas } \\
\hline & & $\begin{array}{l}\text { Component } \\
\text { Matrix }\end{array}$ & Keterangan & $\begin{array}{c}\text { Croncbanch's } \\
\text { Alfa }\end{array}$ & Keterangan \\
\hline \multirow{7}{*}{$\begin{array}{l}\text { Keunggulan E- } \\
\text { Commerce }(X)\end{array}$} & $\mathrm{X} 1$ & 0.841 & Valid & \multirow{7}{*}{0,887} & \multirow{7}{*}{ Reliabel } \\
\hline & $\mathrm{X} 2$ & 0.817 & Valid & & \\
\hline & X3 & 0.607 & Valid & & \\
\hline & $\mathrm{X} 4$ & 0.798 & Valid & & \\
\hline & $\mathrm{X} 5$ & 0.666 & Valid & & \\
\hline & X6 & 0.835 & Valid & & \\
\hline & $\mathrm{X} 7$ & 0.722 & Valid & & \\
\hline \multirow{7}{*}{$\begin{array}{l}\text { Penggunaan E- } \\
\text { Marketplace (M) }\end{array}$} & M1 & 0.833 & Valid & \multirow{7}{*}{0,814} & \multirow{7}{*}{ Reliabel } \\
\hline & M2 & 0.833 & Valid & & \\
\hline & M3 & 0.729 & Valid & & \\
\hline & M4 & 0.584 & Valid & & \\
\hline & M5 & 0.585 & Valid & & \\
\hline & M6 & 0.737 & Valid & & \\
\hline & M7 & 0.672 & Valid & & \\
\hline \multirow{8}{*}{$\begin{array}{l}\text { Manajemen Rantai } \\
\text { Pasokan (Y) }\end{array}$} & Y1 & 0.853 & Valid & \multirow{8}{*}{0,890} & \multirow{8}{*}{ Reliabel } \\
\hline & Y2 & 0.838 & Valid & & \\
\hline & Y3 & 0.773 & Valid & & \\
\hline & Y4 & 0.643 & Valid & & \\
\hline & Y5 & 0.835 & Valid & & \\
\hline & Y6 & 0.713 & Valid & & \\
\hline & Y7 & 0.669 & Valid & & \\
\hline & Y8 & 0.789 & Valid & & \\
\hline
\end{tabular}

Sumber: data peneliti diolah (2020)

\section{Uji Regresi Linier Berganda}

Uji regresi linier berganda dilakukan untuk menganalisis hubungan sebab akibat yang terjadi baik secara langsung antara keunggulan pada E-Commerce (X) terhadap kinerja manajemen rantai pasokan $(\mathrm{Y})$, maupun hubungan tidak langsung melalui penggunaan $E$ Marketplace (M).

\section{Tabel 2}

\section{Ringkasan Hasil Uji Regresi Linier Berganda}

\begin{tabular}{|c|c|c|c|c|}
\hline Model & Unstandardized Coefficient & t hitung & Sig. & Keterangan \\
\hline X-Y & 0.189 & 2.168 & 0.000 & Pengaruh positif dan signifikan \\
\hline X-M & 0.619 & 8.335 & 0.000 & Pengaruh positif dan signifikan \\
\hline M-Y & 0.316 & 3.890 & 0.040 & Pengaruh positif dan signifikan \\
\hline
\end{tabular}

Sumber: Data peneliti diolah (2020)

\section{Analisis Jalur (Path Analysis)}

Analisis jalur kemudian dilakukan untuk melihat pengaruh langsung atau Direct effect $(D E)$ sekaligus pengaruh tidak langsung atau Indirect effect $(I E)$ antar variabel penelitian.

\section{Gambar 1}

Hasil Model Analisis Jalur

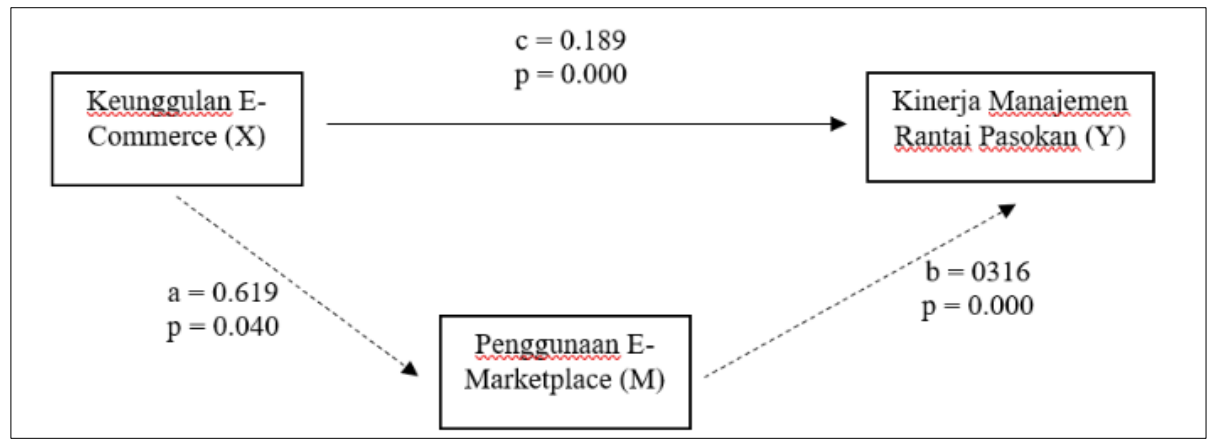

Sumber: Data peneliti diolah (2020) 
Tabel 3

Hasil Analisis Hubungan Langsung dan Hubungan Tidak Langsung

\begin{tabular}{|c|c|c|}
\hline Hubungan antar Variabel & Model & Standard Koefisien Beta \\
\hline Pengaruh langsung/Direct effect (DE) & $\mathrm{X}-\mathrm{Y}$ & $\mathrm{c}=0.189$ \\
\hline Pengaruh tidak langsung/Indirect effect (IE) & $\mathrm{X}-\mathrm{M}-\mathrm{Y}$ & $\mathrm{a} \times \mathrm{b}=0.619 \times 0.316=0.195$ \\
\hline Pengaruh total & $\mathrm{X}-\mathrm{M}-\mathrm{Y}$ & $\mathrm{c}+(\mathrm{a} \times \mathrm{b})=0.189+0.196=0.384$ \\
\hline
\end{tabular}

Sumber: Data peneliti diolah (2020)

Berdasarkan analisis jalur didapatkan bahwa pengaruh langsung (positif dan signifikan) antara Keunggulan pada E-Commerce terhadap Kinerja Manajemen Rantai Pasokan sebesar 0.189. Penelitian ini menunjukan hasil yang serupa dengan penelitan terdahulu seperti pada Harsono (2014) yang menunjukan bahwa E-Commerce berdampak positif pada manajemen rantai pasokan bisnis, juga penelitian dari Balakrishnan \& Geunes (2004) yang menunjukan kolaborasi antara E-Commerce dan Manajemen Rantai Pasokan memberikan peluang dan manfaat positif bagi bisnis.

Pengaruh tidak langsung melalui variabel mediasi Penggunaan E-Marketplace didapatkan 0.195. Hal ini menunjukan pengaruh tidak langsung (IE) memiliki nilai yang lebih besar dibandingkan pengaruh langsung (DE). Penggunaan E-Marketplace secara positif dan signifikan mampu menjadi variabel mediasi yang memperkuat hubungan tidak langsung antara Keunggulan pada E-Commerce terhadap Kinerja Manajemen Rantai Pasokan. Hubungan antara variabel Keunggulan E-Commerce terhadap Kinerja Manajemen Rantai Pasokan, dengan Penggunaan E-Marketplace sebagai variabel mediasi sejalan dengan hasil kajian penelitian sebelumnya (Eng, 2004; Alrubaiee et al., 2012; dan Delfmann et al., 2002).

\section{DAFTAR PUSTAKA}

Alrubaiee, L., Alshaibi, H., \& Al-Bayati, Y. (2012). Relationship between B2B e-commerce benefits, e-marketplace usage and supply chain management relationship between B2B e-commerce benefits, e-marketplace usage and supply chain management. Global Journal of Management and Business Research, 12(9), 23-36.

https://globaljournals.org/GJMBR_Volume12/4-Relationship-between-B2B-ECommerce.pdf

Alzahrani, J. (2019). The impact of e-commerce adoption on business strategy in Saudi Arabian small and medium enterprises (SMEs). Review of Economics and Political Science, 4(1), 73-88. https://doi.org/10.1108/reps-10-2018-013

Awad, E. M. (2007). Electronic commerce from vision to fulfillment (3rd ed.). Pearson.

Balakrishnan, A., \& Geunes, J. (2004). Collaboration and coordination in supply chain management and e-commerce. Production and Operations Management, 13(1), 1-2. https://doi.org/10.1111/j.1937-5956.2004.tb00140.x

Chaffey, D. (2009). E-business and e-commerce management: Strategy, implementation and practice (4th ed.). Pearson.

Chong, W. K., Shafaghi, M., Woollaston, C., \& Lui, V. (2010). B2B e-marketplace: An emarketing framework for B2B commerce. Marketing Intelligence and Planning, 28(3), 310-329. https://doi.org/10.1108/02634501011041444

Delfmann, W., Albers, S., \& Gehring, M. (2002). The impact of electronic commerce on logistics service providers. International Journal of Physical Distribution and Logistics Management, 32(3), 203-222. https://doi.org/10.1108/09600030210426539

Dou, W., \& Chou, D. C. (2002). A structural analysis of business-to-business digital markets. Industrial Marketing Management, 31(2), 165-176. https://doi.org/10.1016/S00198501(01)00177-8

Eng, T. Y. (2004). The role of e-marketplaces in supply chain management. Industrial Marketing Management, 33(2), 97-105. https://doi.org/10.1016/S0019-8501(03)00032-4

Golicic, S. L., Davis, D. F., McCarthy, T. M., \& Mentzer, J. T. (2002). The impact of ecommerce on supply chain relationships. International Journal of Physical Distribution 
and Logistics Management, 32(10), 851-871.

https://doi.org/10.1108/09600030210455447

Guang, Y. (2012). Relationships between E-commerce and supply chain management. Advances in Intelligent and Soft Computing, 165 AISC, 653-658. https://doi.org/10.1007/978-3-642-29637-6_87

Gunasekaran, A., Patel, C., and Tirtiroglu, E. (2001). Performance measures and metrics in a supply chain environment. International Journal of Operations \& Production Management, 21(1/2), 71-87. https://doi.org/10.1108/01443570110358468

Hair, Joseph F., et al. (2009). Multivariate data analysis: A global perspective (7th ed.). Prentice Hall.

Harsono, A. (2014). The impact of e-commerce in supply chain management at Dell Inc. Journal of Multidisciplinary Engineering Science and Technology, 1(3), 3159-40.

Hoffman, D. L., \& Novak, T. P. (2000). How to acquire customers on the web. Harvard Business Review, 78(3), 179-188, 218.

Kareem, T., Owomoyela, S., \& Oyebamiji, F. (2014). Electronic commerce and business performance: An empirical investigation of business organizations in Nigeria.

International Journal of Academic Research in Business and Social Sciences, 4(8), 215223. https://doi.org/10.6007/ijarbss/v4-i8/1090

Koch, H. A. (2003). Business-to-business electronic marketplaces: Membership and use drivers. ProQuest Dissertations and Theses, December, 284.

http://ezproxy.umuc.edu/login?url=https://search.proquest.com/docview/305240694?acc ountid=14580\%0Ahttp://sfx.umd.edu/uc?url_ver=Z39.88-

2004\&rft_val_fmt=info:ofi/fmt:kev:mtx:dissertation\&genre=dissertations+\%26+theses\& sid=ProQ:ABI\%2FINFORM+Global\&atitle=\&tit

Mentzer, J. T., DeWitt, W., Keebler, J. S., Min, S., Nix, N. W., Smith, C. D., \& Zacharia, Z. G. (2001). Defining supply chain management. Journal of Business Logistics, 22(2), 125.

Porter, M. E., \& M. (2001). Strategy and the internet. Harvard Business Review, 79(3), 6378.

Ramanathan, R., Ramanathan, U., \& Hsiao, H. L. (2012). The impact of e-commerce on Taiwanese SMEs: Marketing and operations effects. International Journal of Production Economics, 140(2), 934-943. https://doi.org/10.1016/j.ijpe.2012.07.017

Schneider, G. (2006). Electronic commerce (6th ed.). Thomson Learning Inc.

Turban, E., Outland, J., King, D., Lee, J. K., Liang, T. P., \& Turban, D. C. (2017). Electronic commerce 2018: A managerial and social networks perspective. Springer.

Turban, E, \& Volonino, L. (2009). Information technology for management: Improving performance in the Digital Economy. Wiley.

Van der Vorst, J. G. A. J., Van Dongen, S., Nouguier, S., \& Hilhorst, R. (2002). E-business initiatives in food supply chains; Definition and typology of electronic business models. International Journal of Logistics Research and Applications, 5(2), 119-138. https://doi.org/10.1080/13675560210148641

Zhu, K., \& Kraemer, K. L. (2002). E-commerce metrics for net-enhanced organizations: Assessing the value of e-commerce to firm performance in the manufacturing sector. Information Systems Research, 13(3), 275-295. https://doi.org/10.1287/isre.13.3.275.82 